\title{
TAHKO, TUOMAS E. AN INTRODUCTION TO METAMETAPHYSICS. Cambridgde: Cambridge UnIVersity, 2015. 266 P.
}

Sanderson Molick

Doutorando na Universidade Federal do Rio Grande do Norte

DOI: http://dx.doi.org/10.21680/1983-2109.2018v25n47ID10298

Natal, v. 25, n. 47

Maio-Ago. 2018, p. 165-174

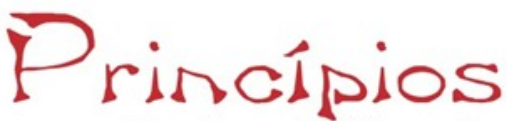

Revista de filosofia E-ISSN: 1983-2109 
Resumo: O livro do filósofo finlandês Tuomas Tahko, An introduction to Metametaphysics, recentemente lançado pela Cambridge University Press (2015) como um dos volumes da série Cambridge Introductions to Philosophy, fornece uma resposta à pergunta: Por que acrescentar um outro "meta" à palavra "metafísica" e tentar falar de uma metametafísica? De acordo com o autor, o termo "metametafísica" serve para designar a área da Filosofia que busca questionar a própria metodologia da metafísica, bem como seu propósito último. Deste modo, a metametafísica pode ser definida como o estudo dos fundamentos e metodologia da metafísica. O livro de Tuomas Tahko é uma notável obra que compila parte considerável do debate contemporâneo sobre o tema.

Palavras-chave: Metafísica analítica; Metaontologia; Metametafísica.

Abstract: The book written by the finnish philosopher Tuomas Tahko, An introduction to Metametaphysics, recently published by Cambridge University Press as a volume of the series Cambridge Introductions to Philosophy, provides an answer to the question: why to add another "meta" to the word "metaphysics" and talk about a "metametaphysics"? According to the author, the term "metametaphysics" refers to the field of Philosophy which seeks to investigate the very methodology of Metaphysics, as well as its ultimate goal. Therefore, metametaphysics might be defined as the study of the foundations and methodology of Metaphysics. Tuomas Tahko's book is a notable contribution which compiles much of the contemporary debate on the theme.

Keywords: Analytical Metaphysics; Metaontology; Metametaphysics. 
CAMBRIDGE INTRODUCTIONS TO PHILOSOPHY

An Introduction to

Metametaphysics

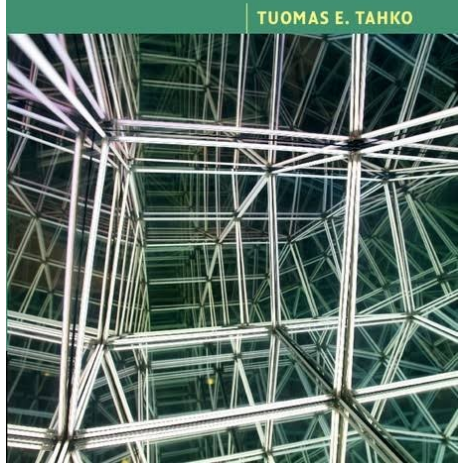

Filósofos são frequentemente conhecidos por sua arrogância e aparente desenvoltura em defender que sua disciplina lhes permite tecer opiniões sobre as outras ciências e demais formas de expressão do conhecimento. Talvez este tipo de atitude encontre justificativa na medida em que certos ramos da Filosofia buscam fornecer teorias gerais o suficiente para abarcar toda a realidade tal como a conhecemos e com a qual interagimos. Um destes ramos, a saber, a Metafísica, foi definido por Aristóteles como uma espécie de "conhecimento primevo", isto é, um tipo de conhecimento tão fundamental que seria capaz de falar das estruturas últimas da realidade. De fato, diz-se que o termo "metafísica" foi introduzido por um bibliotecário ao classificar a parte da obra de Aristóteles que abordava assuntos acerca dos primeiros princípios e primeiras causas do ser.

Por que, então, acrescentar um outro "meta" e tentar falar de uma metametafísica? Não seria isto demasiada arrogância? O livro do filósofo finlandês Tuomas Tahko, An introduction to Metametaphysics, recentemente lançado pela Cambridge University Press (2015) como um dos volumes da série Cambridge Introductions to Philosophy, fornece uma resposta a esta pergunta. De acordo com o autor, o termo metametafísica serve para designar a área da Filosofia que busca questionar a própria metodologia da metafísica, bem como seu propósito último. Deste modo, a metametafísica pode ser definida como o estudo dos fundamentos e metodologia da metafísica. O livro de Tuomas Tahko é uma notável obra que compila parte considerável do debate contemporâneo sobre o tema. 
O livro de Tahko é um dos primeiros a tentar apresentar um mapa geral da recente literatura em torno do tema ${ }^{1}$. Entretanto, faz-se necessário notar que é uma introdução não apenas expositiva, mas que mescla as opiniões do próprio autor. Na literatura sobre o tema, a palavra metametafísica é muitas vezes utilizada como sinônimo de metaontologia. No entanto, Tahko acredita que sua adoção do termo metametafísica é uma melhor escolha por abarcar não só os temas ligados à metaontologia, mas a outras questões tangenciais que exploram as condições de possibilidade da própria metafísica. Tal posição do autor é elemento chave para como estrutura seu livro. A obra possui nove capítulos, e diferentemente de outras introduções ao tema, vários destes capítulos são dedicados aos problemas relativos à metodologia da metafísica. Desta forma, a obra não apenas foca nos problemas ontológicos relativos à existência e à quantificação - foco muitas vezes excessivo em outras obras. No que segue, pretendo expor brevemente a discussão apresentada pelo autor nos primeiros sete capítulos da obra.

O termo "metaontologia" foi introduzido por Peter van Inwagen (1998) no artigo seminal "Meta-ontology". Uma vez que, em "Sobre o que há", a ontologia veio a ser definida por Quine pela pergunta $O$ que há?, a metaontologia, de acordo com van Inwagen, é definida pela pergunta "O que queremos dizer quando perguntamos 'O que há??”. É por esta razão que o livro inicia sua exposição a partir do embate entre Quine e Carnap. Após um rápido primeiro capítulo introdutório, o segundo capítulo aborda os motivos da discordância dos dois filósofos acerca da interpretação correta do quantificador existencial. Embora também seja possível encontrar uma breve introdução ao pensamento de Meinong e de como este se situa no debate atual entre allists e noneists ${ }^{2}$, a linha de desen-

\footnotetext{
${ }^{1}$ Embora não seja o primeiro a utilizar o termo metametafísica.

${ }^{2}$ Aqui foi escolhido manter os termos no original em inglês por não se conhecer palavras análogas no português. Optaremos por manter os termos origi-
} 
volvimento do segundo capítulo busca introduzir o leitor às reformulações mais atuais do pensamento de Quine e Carnap. Algumas posições de neo-carnapianos, tais como a de Thomas Hofweber e sua distinção entre domínios externos e internos de quantificação, bem como a discussão do quarto ontológico de Cian Dorr, são contrastadas com outras posições concernentes à discussão.

O terceiro capítulo segue a mesma linha de exposição do segundo para agora focar no debate sobre comprometimento ontológico. Embora tenha sido exposto que o debate acerca da forma adequada de compreender o quantificador existencial remonte ainda às posições de Quine, Meinong e Russell, Tahko não dedica mais tempo a expor a visão de tais filósofos. Em lugar disso, o capítulo inicia com as razões históricas que levaram a interpretação do quantificador existencial enquanto existencialmente carregado, isto é, enquanto comprometido existencialmente. A linha de desenvolvimento do capítulo consiste no debate sobre qual deve ser a questão central da ontologia. De um lado, alguns autores afirmam que a preocupação central da ontologia deve ser a de buscar responder se o quantificador existencial deve ser interpretado de maneira unívoca (univocal) ou ambígua (equivocal). Uma seção é dedicada à exposição da ideia de variação de quantificação a partir da teoria de Agustín Rayo, para quem há uma diferença fundamental entre indagar acerca do comprometimento existencial acarretado por uma sentença e o comprometimento existencial acarretado por uma teoria semântica. O capítulo também apresenta a discussão entre a teoria de Eli Hirsch acerca das disputas meramente verbais (merely verbal disputes) e a visão de Theodore Sider sobre a existência de um univocalismo no que diz respeito às questões da ontologia. A última seção é dedicada a introduzir a posição de Kit Fine, segundo a qual as disputas

nais sempre que a tradução para o português possa acarretar má compreensão. 
existenciais não devem ser parte central da metaontologia, mas, sim, o debate acerca de quais são as porções mais fundamentais da realidade, o que consolida as bases para a apresentação dos trabalhos posteriores de Fine sobre fundamentalidade (fundamentality).

O capítulo quatro trata das posições mais gerais em metaontologia. O início é uma longa discussão sobre a melhor forma de definir realismo/anti-realismo ontológico. O autor elenca uma cuidadosa exposição das razões para as diferentes definições da terminologia e, por fim, resolve definir realismo ontológico como a tese de que há fatos objetivos na realidade. Em seguida, é feita uma exposição do deflacionismo ontológico, sendo dada bastante atenção à posição de Amie Thomasson e sua ontologia de respostas fáceis. O autor é muito cuidadoso ao separar o deflacionismo ontológico do realismo/antirrealismo ontológico. Ainda é feita uma breve exposição de como é possível combinar o deflacionismo ontológico com outras posições. O capítulo então avança para a forma mais extrema de deflacionismo ontológico, o convencionalismo. Ênfase especial é dada ao convencionalismo defendido por Achille Varzi, e o convencionalismo modal proposto por Allen Sidelle. A fim de fazer o contraste com as posições tratadas anteriormente, o capítulo continua com uma exposição do realismo ontológico de Theodore Sider e sua intenção de mapear as articulações (joint) mais fundamentais da realidade. Tahko apresenta de maneira bastante clara a posição de Sider, sobretudo ao relacionar o realismo ontológico sideriano e sua visão acerca do quantificador existencial. Alguns problemas ligados à ideia de jointcarving também são apresentados ao apelar para uma discussão acerca das propriedades fundamentais do elétron. O capítulo termina com uma rápida consideração sobre os problemas que o ontólogo realista enfrenta em face de seus detratores. Com isto, torna-se necessária uma investigação dos fundamentos epistêmicos da própria disciplina, isto é, daquilo que poderia conferir a solidez das ferramentas utilizadas pelo ontólogo realista. Uma vez que o 
próprio autor subscreve a importância deste projeto, o resto do livro se dedica à tal empreitada.

O quinto capítulo é sobre grounding e dependência ontológica, duas ferramentas bastante discutidas no debate metafísico contemporâneo. Embora a noção de fundamento remonte ao pensamento de Aristóteles, a palavra grounding aparece no cenário contemporâneo a partir da obra de Kit Fine. De acordo com Tahko, grounding pode ser entendido como "explanação metafísica". Para ser mais preciso, quando dizemos que $\mathrm{x}$ está fundamentado (grounded) em algum y, usualmente pensamos que y explica $\mathrm{x}$. Assim, a palavra grounding remete a uma ideia de prioridade, aos elementos mais fundamentais capazes de "explicar" um outro objeto. Após uma breve incursão no conceito de grounding, o capítulo adentra de forma mais específica numa das formas mais comuns de grounding, a dependência ontológica. Algumas noções de dependência ontológica e suas variações são apresentadas de um ponto de vista formal (embora pouco simbolismo seja usado), como as formas de dependência existencial e modal. O capítulo prossegue então para uma exposição das motivações para uma análise não-modal da dependência ontológica. Em seguida, várias formas de grounding são expostas a partir do artigo de Kit Fine (2012), A guide to Ground. Tahko é bastante cauteloso ao tentar diferenciar grounding de necessidade causal, superveniência modal e causalidade física, o problema em aberto acerca de que tipo de causalidade está relacionada ao grounding é colocado de forma bastante clara. Por fim, o capítulo encerra com uma exposição das relações entre grounding e fazedores-de-verdade, e tenta explicar por que a discussão sobre fazedores-de-verdade, em certa medida, se transformou na discussão sobre grounding.

O capítulo seis é sobre fundamentalidade e níveis de realidade. O fio condutor é a ideia de que toda a realidade possui uma estrutura hierárquica de níveis. O capítulo inicia com a exposição do problema da existência de níveis fundamentais da realidade e sua relação com dependência ontológica. $\mathrm{O}$ autor analisa as diversas 
posições contra e a favor da teoria da fundamentalidade mereológica. O capítulo prossegue com uma exposição da noção de fundamentalidade primeiramente proposta por Paul Oppenheimer e Hilary Putnam para explicar como esta foi sendo revisitada de modo a desembocar hoje na discussão entre pluralistas e monistas acerca dos níveis fundamentais da realidade. O autor elenca argumentos da Física para atacar a existência de objetos mereológicos fundamentais a partir da obra de Ladyman \& Ross. Em face da insuficiência das noções de fundamentalidade discutidas anteriormente, o capítulo continua com uma proposta mais geral de fundamentalidade, a saber, a fundamentalidade ontológica genérica. A ideia de uma fundamentalidade ontológica genérica visa produzir uma concepção de fundamentalidade que não depende de objetos mereológicos como itens necessários a uma teoria acerca das relações entre o todo e suas partes. A possibilidade de uma fundamentalidade ontológica sem objetos mereológicos tem recebido bastante atenção no cenário filosófico atual.

O capítulo sete aborda a epistemologia da metafísica. Em suma, o que está em jogo é saber de que modo, e se, é possível termos acesso ao conhecimento metafísico. O capítulo inicia com uma breve exposição dos problemas enfrentados pela distinção entre conhecimento a priori/a posteriori para concluir que qualquer abordagem que tentar fundamentar o conhecimento metafísico no conhecimento a priori/a posteriori terá que lidar com tais problemas. Com isto, o autor decide desenvolver o capítulo a partir do candidato mais atual, o conhecimento modal. A primeira via é introduzida logo em seguida, a saber, a do racionalismo modal. A relação entre racionalismo modal e métodos a priori é apresentada a partir de uma comparação entre as abordagens que tentam basear o conhecimento modal no conceito de conceivability e aquelas que se baseiam no conceito de essência. No curso da exposição, a tentativa de Timothy Williamson (2007), em The Philosophy of Philosophy, de explicar o conhecimento modal em termos contrafatuais é também discutida. Após concluir com os problemas relaciona- 
dos ao racionalismo modal, o capítulo continua com uma exposição do empirismo modal, bem como de suas próprias dificuldades. Por fim, a última seção do capítulo elenca as tentativas de combinar o conhecimento a priori e a posteriori a partir de uma relação mútua capaz de alçar o conhecimento modal e permitir o nosso acesso a cenários metafísicos, ideia defendida pelo próprio autor já em alguns de seus artigos.

Os dois capítulos restantes são desdobramentos naturais da discussão sobre a epistemologia do conhecimento metafísico. Vários problemas são abordados e discutidos em detalhe, como o papel das intuições enquanto via de acesso ao conhecimento metafísico e a relação entre ciência e metafísica. Apesar de o livro ter a intenção de ser uma introdução, a compreensão de muitos tópicos do livro pressupõe um conhecimento prévio de lógica e metafísica. O livro não é direcionado para leitores leigos em Filosofia. Mais ainda, alguns exemplos utilizados podem dificultar um pouco a leitura para aqueles que não tiveram qualquer introdução à Física Moderna, em especial, à Mecânica Quântica. Entretanto, o autor é cordial ao apontar para o leitor a possibilidade de saltar os trechos dos livros em que tais elementos serão utilizados e expostos. No geral, o livro é muito bem escrito e, certamente, serve como guia para aqueles que buscam ter um primeiro contato com o tema. As referências utilizadas também são fundamentais para aqueles que buscam algum guia no debate atual acerca dos problemas apresentados.

A obra de Tahko se destaca enquanto manual de introdução ao tema. O outro manual de introdução à metaontologia, Ontology and Metaontology: A contemporary guide, escrito por Francesco Berto e Matteo Plebani (2015), possui uma orientação e um estilo de apresentação bastante diferente do livro de Tuomas Tahko. Embora ambos os livros iniciem a partir de temas semelhantes, somente o livro de Tahko explora questões ligadas à metodologia e à epistemologia da Metafísica. Em lugar disso, o livro de Berto \& Plebani explora o debate acerca dos objetos abstratos e seu esta- 
tuto ontológico. Ademais, o livro de Tahko mescla as próprias opiniões do autor às discussões nos respectivos capítulos. Algumas posições apresentadas pelo autor podem ser encontradas nos seus artigos, ou até mesmo na sua tese de doutorado, The Necessity of Metaphysics. A obra de Tahko é, certamente, leitura obrigatória para aqueles que querem ser introduzidos ao tema, ou que querem conhecer mais sobre os elementos que possibilitaram a virada neoaristotélica na Metafísica contemporânea.

\section{Referências}

BERTO, Francesco, PLEBANI, Matteo. Ontology and metaontology: a contemporary guide. Londres: Bloomsbury, 2015.

FINE, Kit. A guide to Ground. In: CORREIA, Fabrice; SCHNIEDER, Benjamin (Ed.). Metaphysical grounding: understanding the structure of reality. Cambridge: Cambridge University Press, 2012. p. 37-80.

INWAGEN, Peter van. Meta-ontology. Erkenntnis. v. 48, n. 2, 1998, p. 233-250.

TAHKO, Tuomas E. An Introducion to Metametaphysics. Cambridge: Cambridge University, 2015.

WILLIAMSON, Timothy. The philosophy of philosophy. Oxford: Blackwell, 2007.

Resenha recebida em 3/10/2016, aprovada em 20/05/2018 